\title{
Pulmonary Arterial Hypertension and Pregnancy
}

\author{
Shibba Takkar Chhabra ${ }^{1}$ Gurleen Kaur ${ }^{2}$ Gagandeep Nagi ${ }^{3}$ Rohit Tandon ${ }^{1}$ Abhishek Goyal ${ }^{1}$ \\ Bhupinder Singh ${ }^{1}$ Naved Aslam ${ }^{1}$ Bishav Mohan ${ }^{1} \quad$ Gurpreet Singh Wander ${ }^{1}$
}

\author{
${ }^{1}$ Department of Cardiology, Dayanand Medical College and \\ Hospital, Unit Hero DMC Heart Institute, Ludhiana, Punjab, India \\ ${ }^{2}$ Department of Medicine, Dayanand Medical College and Hospital, \\ Ludhiana, Punjab, India \\ ${ }^{3}$ Department of Research and Development (Cardiology), Dayanand \\ Medical College and Hospital, Ludhiana, Punjab, India
}

Address for correspondence Shibba Takkar Chhabra, (DM Cardiology), Department of Cardiology, Dayanand Medical College and Hospital, Unit Hero DMC Heart Institute, Ludhiana 141001, Punjab, India (e-mail: shibbachhabra@yahoo.com).
Abstract
Keywords
- endothelin receptor antagonist
- mean pulmonary arterial pressure
- pulmonary arterial hypertension
- pulmonary cardiac wedge pressure
- pulmonary hypertension
- pulmonary vascular resistance

Pulmonary hypertension in pregnancy has always scared the treating physician and gynecologist due to reported high mortality since ages. The upcoming therapies targeting pulmonary hypertension (calcium channel blockers, nitric oxide, endothelin receptor antagonist, phosphodiesterase type 5 inhibitors) and improvement in hemodynamic monitoring and intensive management in pulmonary arterial hypertension (PAH) specialist centers give a ray of hope to these patients. Termination of pregnancy continues to be a management modality in pregnant patients with $\mathrm{PAH}$. Multidisciplinary approach targeting $\mathrm{PAH}$ - and pregnancy-specific therapy in this subset can prove rewarding. Larger multicentric studies in the present era of new pharmacologic agents targeting PAH are required.

\section{Introduction}

Pulmonary hypertension $(\mathrm{PH})$ is a multidisciplinary ailment defined as a sustained elevation in mean pulmonary arterial pressure (mPAP) $\geq 25 \mathrm{~mm} \mathrm{Hg}$ at right heart catheterization. Pulmonary arterial hypertension (PAH) is a subset of $\mathrm{PH}$ described by left ventricular filling pressure of $\leq 15 \mathrm{~mm} \mathrm{Hg}$ and pulmonary vascular resistance (PVR) $>3$ Wood units. ${ }^{1}$ Intimal fibrosis, increased medial thickening causing pulmonary arterial occlusion, and classic plexiform lesion resulting in high pulmonary vascular pressure characterize PAH. It is commonly seen in women. The mean age of diagnosis is 37 years, and the women-to-men ratio is $1.7: 1 .^{2}$ Idiopathic PAH (IPAH) is encountered occasionally but is rapidly progressing. If left untreated, the median survival age is only 2.8 years, ${ }^{3}$ and with treatment, the median survival age is 5 to 6 years.

Female PAH patients may become evident for the first time during the course of pregnancy. Pregnancy with PAH has mortality rate as high as $56 \%$ in earlier reports in 19 th century to 25 to $30 \%$ in relatively recent reports. ${ }^{4}$ Hence pregnancy is not recommended in these patients.

Recent advances show that a multidisciplinary approach to the disease and newer, potent drugs have resulted in a considerable decrease in the mortality rate. The approach may result in a better prognosis and improved quality of life, resulting in healthier outcomes. ${ }^{5}$

Nonetheless, even with the best new medical therapy, a lot of challenges still have to be overcome. This review article discusses the etiology, pathophysiology, and pertinent management during pregnancy, delivery, and postpartum period. This article is an attempt to look at prevalent clinical practices and suggest the possible amendments in management of PAH based on recent advances.

\section{Hemodynamic Alteration in a Pregnant Woman}

Noteworthy hemodynamic alterations occur normally during the course of pregnancy as shown in - Fig. 1 . These changes 


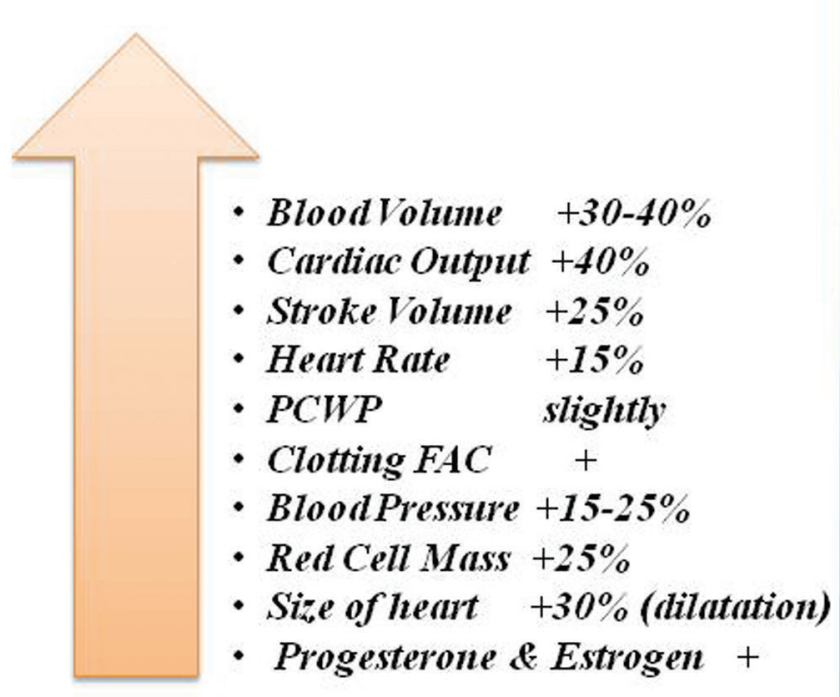

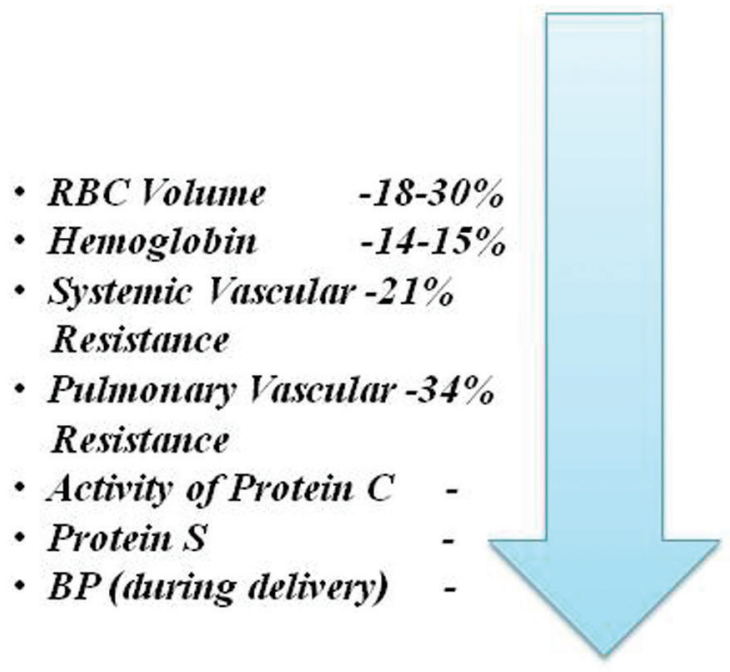

Fig. 1 Physiologic cardiovascular changes in pregnancy. BP, blood pressure; FAC, factors; PCWP, pulmonary capillary wedge pressure; RBC, red blood cell.

develop gradually from fifth week onward and continue up to a few weeks after delivery. Estrogen and progesterone have a vasodilatory effect causing venous distensibility and further decrease in the systemic vascular resistance (SVR). Also, tidal volume is increased despite an elevated diaphragm and normal respiratory rate. This ascent in tidal volume leads to rise in minute volume and alkalosis with a decreased functional capacity. ${ }^{6}$ Hypercoagulability in pregnancy leads to a surge in production of clotting factors and fibrinogen, decreased production of protein $\mathrm{S}$, and resistance to activated protein $C$ leading to an increased danger of thromboembolic event. The enlarging uterus compresses the inferior vena cava (IVC) resulting in decreased venous return to the right ventricle. ${ }^{7}$ These factors put stress on the right ventricle leading to an increased possibility of right-sided heart failure in pregnant women with $\mathrm{PAH}$.

Intra- and peripartum changes in pressure and volume put the patient at a liability of developing right-sided heart failure. Main changes occur in cardiac output (CO) and the blood pressure (BP), especially during labor and delivery. About $500 \mathrm{~mL}$ of blood from the uterus gets deflected to maternal circulation with each uterine contraction ${ }^{8}$ leading to increased $\mathrm{CO}$ and systemic BP by approximately 15 to $25 \%{ }^{9,10}$ Contrary to this, during delivery, the systemic BP might fall due to vasovagal response or increased blood loss that is approximately $500 \mathrm{~mL}$ in normal vaginal delivery and $1,000 \mathrm{~mL}$ in delivery through cesarean section. CO changes vary across the peripartum period, increasing by $15 \%$ in early labor and by 34\% during normal vaginal delivery at full cervical dilatation. ${ }^{11}$ In a cesarean section delivery with spinal anesthesia, it increases by $47 \%$ with a $39 \%$ decrease in the SVR,, 612 and during postpartum period, it increases up to $80 \%$ in lieu of the autotransfusion from the involuting uterus and absorption of pedal edema. These antagonistic factors make the management of labor and delivery immensely complex. In addition, complications during delivery such as hemorrhage, infection, analgesia, and anesthesia can pose immense stress on the woman's cardiovascular system (-Fig. 2).

The clinical classification of $\mathrm{PH}^{1}$ (ESC/ERS guidelines 2016) is shown in - Fig. 3.

Chiefly women in the child-bearing age get affected by IPAH and PAH related to connective tissue ailments. ${ }^{13}$ IPAH is uncommon, rapidly progressing, and fatal if not managed on time. Association with connective tissue disorders is frequent, the highest being with scleroderma, that is, with CREST (calcinosis, Raynaud's phenomenon, esophageal dysmotility, sclerodactyly, and telangiectasia) syndrome 10 to $20 \%$ and with SLE $10 \%{ }^{14}$

Pregnancy has a lot of symptoms in common with PAH such as shortness of breath, weakness, fatigue, abdominal discomfort, syncope. ${ }^{15}$ Sometimes women present with their first symptom of PAH during pregnancy. Hence, high index of suspicion is required on the part of the physician to recognize the symptoms and send the patient for a further evaluation, that is, echocardiography. Assessment of pulmonary pressure by echocardiography is considered an effective screening method. ${ }^{16}$ However, invasive hemodynamic monitoring, that is, right heart catheterization is required for confirming not only the diagnosis but also looking at how severe the disease pattern is. This helps in determining the prognosis and treatment course. It is the gold standard investigation for PAH with minimum complications as reported by a survey of 7,218 catheterization cases resulting in only $1.1 \%$ complications. ${ }^{17}$

\section{Maternal and Fetal Mortality}

The mortality rate in $\mathrm{PAH}$ women is considerably high in the studies reported in the past. From 1978 to 1996 , a 


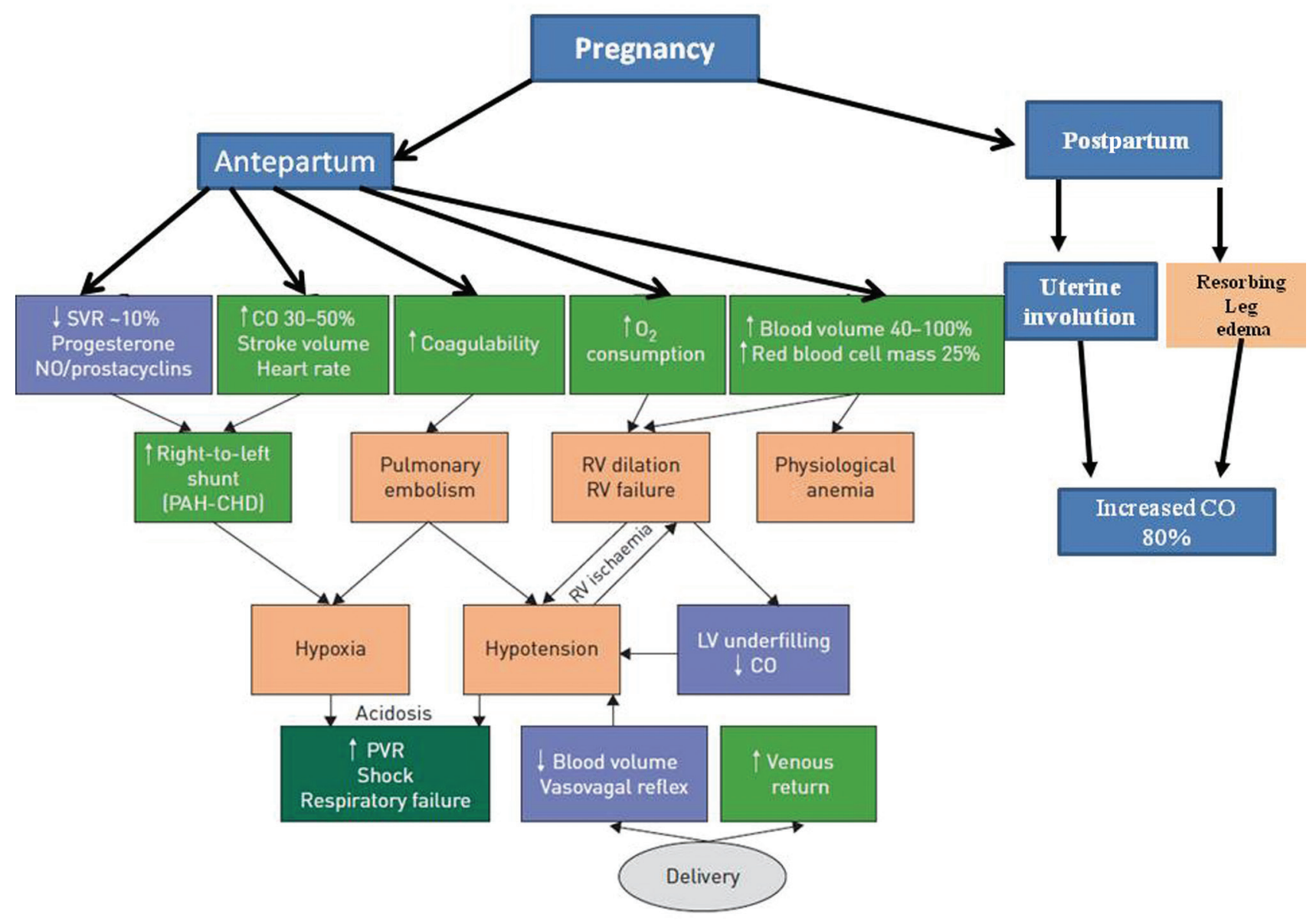

Fig. 2 Pathophysiology in relation to clinical manifestations of pulmonary arterial hypertension (PAH) during pregnancy. CHD, congenital heart disease; CO, cardiac output; LV, left ventricular; PVR, pulmonary vascular resistance; RV, right ventricular; SVR, systemic vascular resistance.

retrospective review study by Weiss ${ }^{18}$ et al shows that mortality related to primary IPAH is $30 \%$; PH associated with Eisenmenger's syndrome is 36\%; and PH related with other diseases such as connective tissue disorders, liver disease, and thromboembolic phenomenon is $56 \%{ }^{4}$ With the advances in management techniques and new and potent medication, there seems to be a hope in the decrease in maternal mortality rates. A retrospective study from 1997 to 2015 was undertaken by Ladouceur ${ }^{5}$ et al on a cohort of 28 pregnant women with PAH stated that mortality rate in PAH women related with congenital heart disease in their cohort is $5 \%$. Silwa ${ }^{19}$ et al report that mortality due to IPAH is still as high as $43 \%$. Most deaths occurred near delivery or within 1 month post-delivery. ${ }^{20}$ The figures are prohibitively high so that the best method to manage is discontinuation of pregnancy. The comparison between the studies is limited as they are multicentric with varying levels of quality of care. Severity of the disease also creates a variation in the results.

Among the pregnant women with PAH, risk stratification has been done by several authors. Studies outline low-risk pregnancy in PAH women as: PAH effectively managed by PAH-specific therapy, response to calcium channel blockers (CCBs), and low PVR. ${ }^{21}$ High-risk pregnancies are the ones with uncontrolled PAH, high PVR, and first pregnancy ( - Fig. 4). ${ }^{21-23} \mathrm{~A}$ study by Katsuragi ${ }^{24}$ et al concluded that the level of mPAP prior to and in early stages of pregnancy is a significant indicator of pregnancy outcomes.

The rate of neonatal complications is high, and the mortality can range from $7 \%$ to up to $13 \%$ in various reports. The main complications faced include miscarriages $5.6 \%$, fetal death $2 \%$, preterm delivery $21.7 \%$, low birth weight $19 \%$, and neonatal death $0.7 \% .^{20}$ Intrauterine growth restriction (IUGR), maternal distress, and premature delivery are the usual causes of death. Scarce data are available on fetal morbidity.

\section{Counseling Guidelines in Pregnant Women with Pulmonary Arterial Hypertension}

Maternal and fetal risks are high in women of child-bearing age with PAH; therefore, those women are advised against pregnancy. ${ }^{1,9,25}$ This must be clarified at the time of diagnosis of PAH. They and their families must be counseled at a $\mathrm{PH}$ center with expertise in management of pregnancy in PAH. ${ }^{17,25,26}$ These patients must be advised early about the effective contraceptive methods. Barrier methods are safe but unpredictable. ${ }^{1}$ Intrauterine copper devices (IUCDs) may 


\section{Pulmonary arterial hypertension}

\section{Classification of pulmonary hypertension}

1.1 Idiopathic

1.2 Heritable

\subsubsection{BMPR2 mutation}

1.2.2 Other mutations

1.3 Drug- and toxin-induced

1.4 Associated with:

A.4.1. Connective tissue disease

1.4.2. Human immunodeficiency virus (HIV) infection

1.4.3. Portal hypertension

1.4.4. Congential heart diseases

1.4.5. Schistosomiasis

1'.Pulmonary venoocclusive disease and/or pulmonary capillary hemangiomatosis

1'.1 Idiopathic

1'.2 Heritable

1'.2.1 EIF2AK4 mutation

$1^{\prime} .2 .2$ Other mutations

1'.3 Drug-, toxin-, and radiation-induced

$1^{\prime} .4$ Associated with:

$1^{\prime} .4 .1$ Connective tissue disease

1'.4.2 HIV infection

1 "Persistent pulmonary hypertension of the newborn

2.Pulmonary hypertension due to left heart disease

3.Pulmonary hypertension due to lung diseases and/or hypoxia

4.Chronic thromboembolic pulmonary hypertension and other pulmonary artery obstructions

5.Pulmonary hypertension with unclear and/or multifactorial mechnisms

Fig. 3 Classification of pulmonary hypertension.

cause vasovagal reactions during insertions and therefore severe adverse effects. ${ }^{25,26}$ Hormone-based methods may be used, especially the progesterone-only pills. ${ }^{25}$ However, the risk of thromboembolic phenomenon might be increased. ${ }^{27}$ Anticoagulation does not protect entirely against thrombotic events. Permanent methods may not be wanted in many women who may demand temporary contraception. They also bear the risk of complications and anesthesia. Hence dual contraception, that is, using two methods of contraception, is recommended, especially in women on endothelin receptor antagonists (ERAs)-bosentan due to its interactions with progesterone-based methods of contraception..$^{1,7}$

In vitro fertilization and egg harvesting are not advocated in PAH women due to the possibility of ovarian hyperstimulation and venous thromboembolism (VTE).
If a PAH woman desires pregnancy, genetic screening and counselling must be done, ${ }^{28}$ especially if it is heritable $\mathrm{PAH}$ and/or a mutation in associated gene is discovered. It is important to consider the disease etiology of PAH as it affects the treatment strategies. For example, if $\mathrm{PAH}$ is associated with connective tissue disorder being treated with immunosuppressants, pregnancy is contraindicated. Individualization of patients regarding their management during post-pregnancy is important as limited data are available in this sector to generalize the management protocol.

\section{Management Strategies}

Improvement in survival rates in PAH and pregnancy is a result of advanced management modalities and the utilization of a 


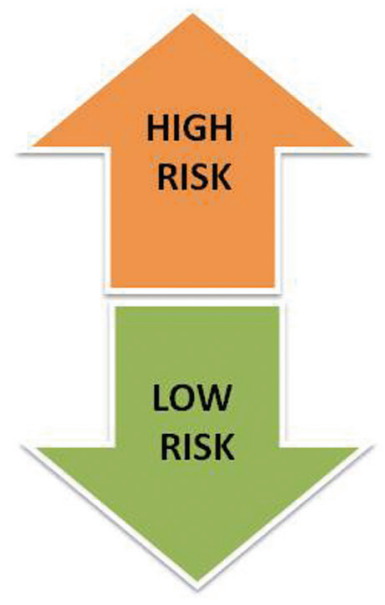

1.Uncontrolled PAH

2.First Pregnancy

3.High PVR

1.Well controlled PAH

2.Low PVR

3.Responder to CCB's

Fig. 4 Risk stratification of pregnant women with pulmonary arterial hypertension (PAH). CCB, calcium channel blocker; PVR, pulmonary vascular resistance.

multidisciplinary approach. ${ }^{15,19,22,29}$ However, the rates are still prohibitively high so that if pregnancy happens, the woman should be counseled to undergo therapeutic abortion that should ideally take place before 22 weeks of gestation. ${ }^{7}$ Any delay beyond this has shown to accelerate the risk of mortality. $\mathrm{PAH}$ in pregnancy is a complex clinical entity; hence, it should be managed in a PAH specialist center that has expertise in treating PAH in pregnancy and has a collaborative team of an obstetrician, cardiologist, pulmonologist and anesthetist, geneticist, and intensivist (-Fig. 5). Women who decide to continue the pregnancy should be kept under close monitoring either by close follow-ups or elective hospitalization. Regular echocardiographic monitoring and fetal evaluation for growth retardation are important alongside the regular clinical evaluation. ${ }^{25}$ Often, second-trimester hospitalization is pertinent due to increased risk of hemodynamic complications and premature labor. ${ }^{30,31}$ There is no standard treatment approach to deal with pregnant patients with PAH. Often, the management is tailored according to individual patient's severity of the ailment and their present condition and should be discussed with the patients priorly.

Management of PAH during pregnancy can be dealt with as PAH- and pregnancy-related issues (-Fig. 6).

\section{Influence of Pregnancy on Management Strategies}

Pregnancy being a hypercoagulable state makes thrombotic arteriopathy a significant marker of PAH and pregnancy that may alter the course and final outcome of the patient. ${ }^{32}$ Anticoagulation treatment is started in patients suffering from IPAH, heritable PAH, and PAH due to secondary causes. Previous studies show that anticoagulation therapy is given in an average to 52 to $68 \%$ women. $^{21}$ As anticoagulants, vitamin $\mathrm{K}$ antagonists are contraindicated as they cause fetal craniofacial malformations during the first trimester, fetal hemorrhage, spontaneous abortion, and malformation of the central nervous system. Warfarin is teratogenic as it crosses the placenta; hence, it is contraindicated. Low-molecular-weight heparin (LMWH) and enoxaparin are the drugs of choice; $1 \mathrm{mg} / \mathrm{kg}$ as a subcutaneous injection is

\section{CARDIOLOGIST: \\ - HEMODYNAMICMONTORING \\ - PREVENTION ANDTREATMENT OF RIGHT HEART FAILURE}

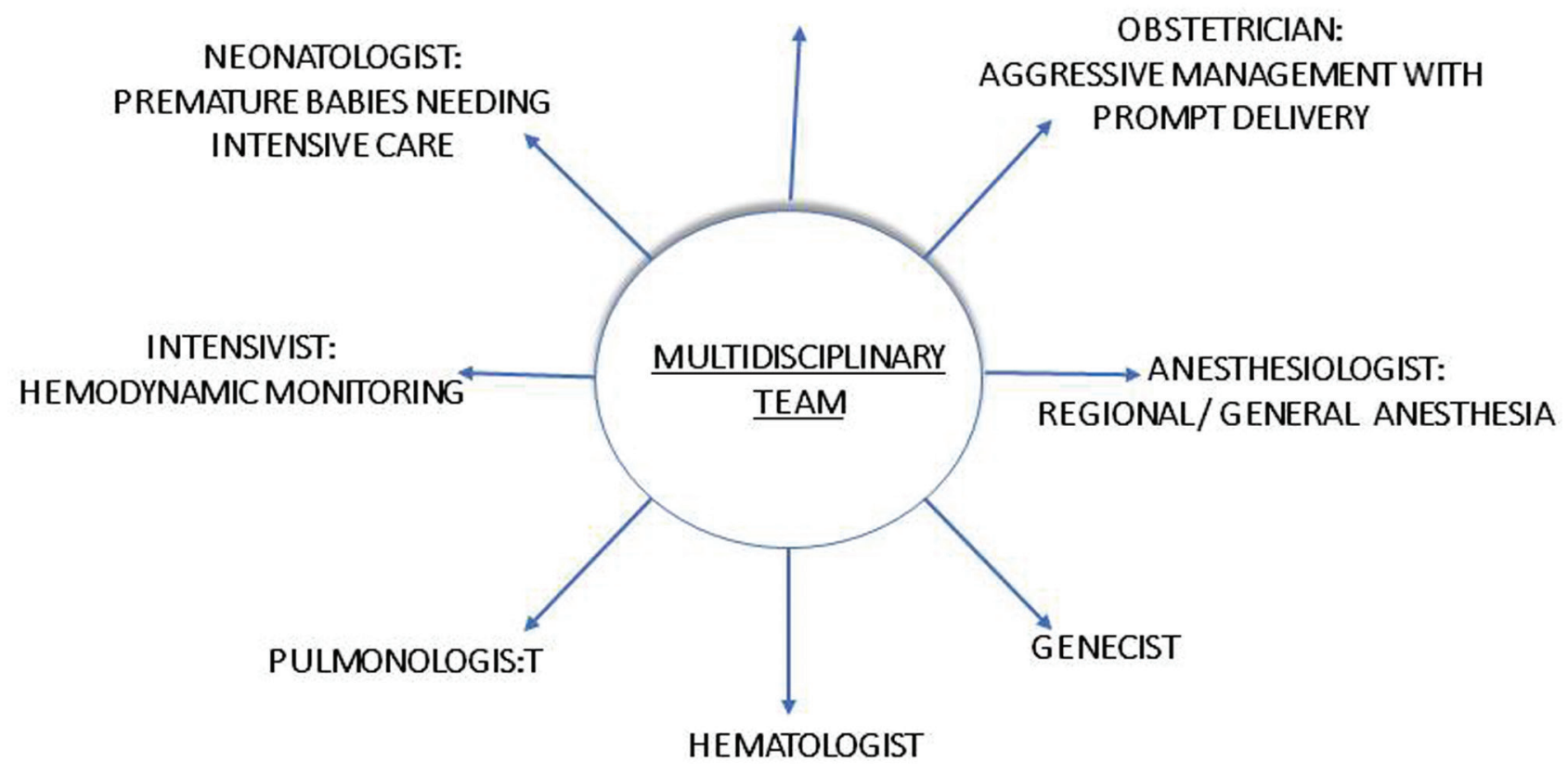

Fig. 5 Multidisciplinary approach toward pulmonary arterial hypertension and pregnancy. 


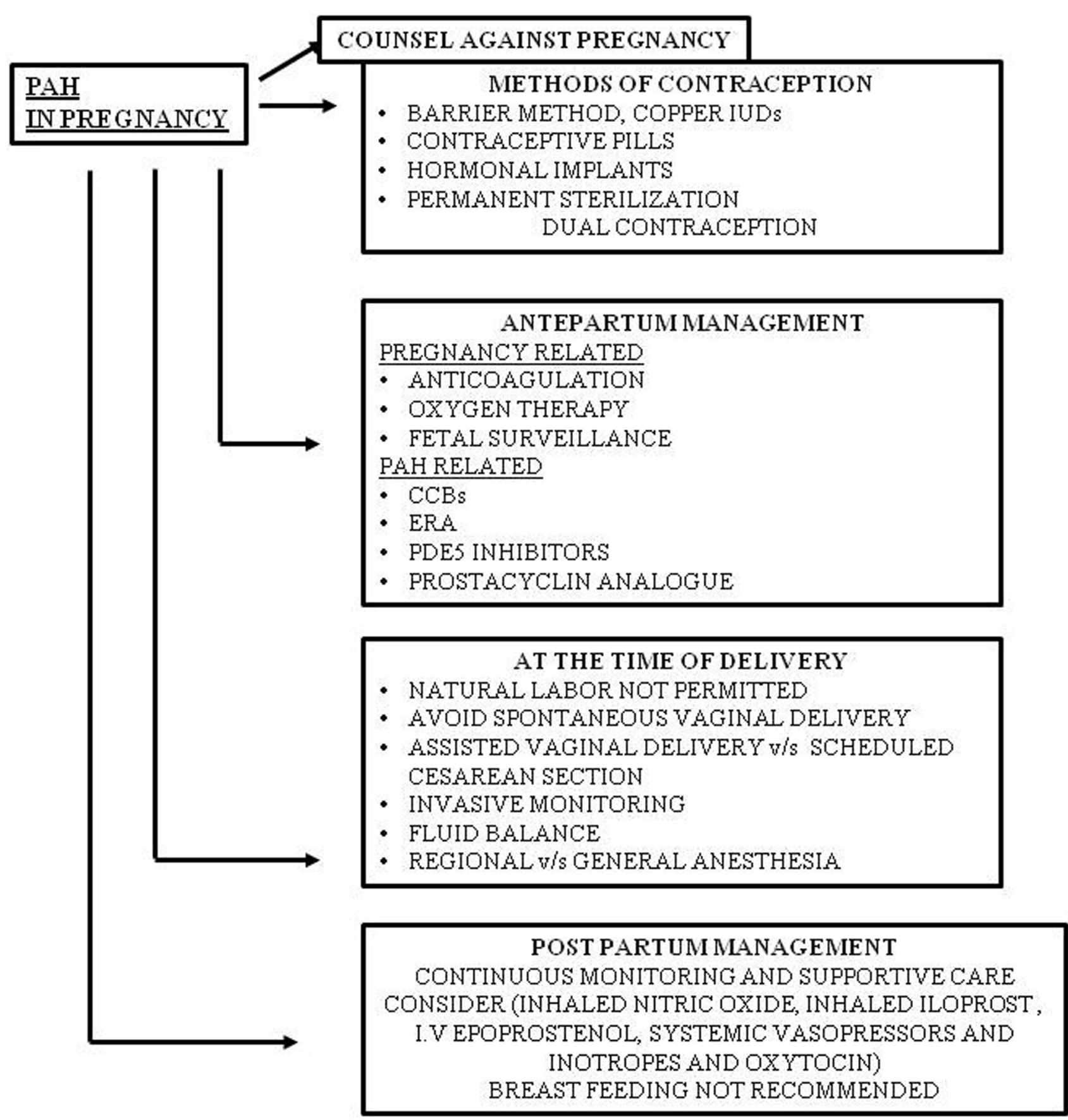

Fig. 6 Management of PAH with pregnancy. CCB, calcium channel blocker; ERA, endothelin receptor antagonist; PAH, pulmonary arterial hypertension; PDE5, phosphodiesterase 5.

given. Heparin is the mainstay of treatment in acute venous thromboembolic event in pregnancy. ${ }^{33}$ It does not cross the placental barrier; hence, it is safe during pregnancy.

Increased fluid retention and blood volume occur in pregnancy and are also signs of right-sided heart failure; hence, it is important to manage peripheral edema. Patients are suggested to not lie on their backs to avoid pressure on the IVC. Diuretics can be used to manage edema, and torsemide and furosemide are preferred choices. Spironolactone is not given because of its antiandrogenic effects. ${ }^{10,25}$ A disadvantage of diuretics is that they reduce the blood flow to the placenta; hence, they should be used with caution. Oxygen therapy is given in patients with hypoxia as indicated by blood gas parameters.

For PAH patients insisting to continue the pregnancy, regular monitoring at a center dedicated to treating these patients is advised. At times, elective admission may be considered up to delivery. Besides clinical examination, close monitoring should include regular echocardiograms and assessment of fetal well-being. ${ }^{25}$ Second-trimester hospitalization may be required due to the possible risk of premature labor and hemodynamic compromize. ${ }^{30,31}$ Patients should be assessed timely for lung transplantation that may be required in hours of crisis in high-risk patients. 


\section{Influence of Pulmonary Arterial Hypertension on Management Strategies}

The drugs available for management of PAH and pregnancy include CCBs, ERA, nitric oxide (NO), phosphodiesterase type 5 (PDE5) inhibitors, and prostacyclin analogues. CCBs are the recommended drugs, ${ }^{34}$ but their use may be limited due to longer half-life and negative inotropic effects. ${ }^{35}$ Moreover, nifedipine, amlodipine, and diltiazem are pregnancy category C drugs and should be used with caution. Uncomplicated pregnancy is reported in a series of patients on CCBs. ${ }^{21}$

The current guidelines of European Society of Cardiology and European Respiratory Society advocate that pregnant women with PAH should be continued with PAH-specific treatment ${ }^{1}$ except for ERAs that being teratogenic should be changed. Therefore, once pregnancy detected, ERA should be stopped and another drug should be started. There is no need to discontinue ERA before pregnancy even in women planning to get pregnant.

Nitric oxide is a potent vasodilator and antiproliferative for pulmonary vasculature. It does so by activating cyclic guanosine monophosphate (cGMP). PDE5 inhibitors inhibit the activation of cGMP by NO and decrease its efficacy. Hence, PDE5 inhibitors inhibit their activity and potentiate the function of NO. Presently used oral drugs are sildenafil and tadalafil. ${ }^{36}$ They are category $\mathrm{B}$ drugs and can be given in pregnancy. Throughout labor NO may be continuous inhaled to decrease the pulmonary arterial pressure (PAP).

Prostacyclin pathway is the most potent route. These drugs can be administered via different routes: Epoprostenol or treprostinil can be given intravenously under supervision (category B pregnancy drugs). Treprostinil can also be given subcutaneously, and iloprost can be administrated by inhalation but is not preferred (category C pregnancy drug). ${ }^{37}$

If a patient deteriorates on one drug regimen, combination of drugs of different mechanism can be used. ${ }^{38}$

\section{Delivery Management in Pulmonary Arterial Hypertension}

At the time of delivery, PAH women should not go into natural labor ideally, and the delivery should always be planned and under controlled environment. There is a difference in opinion in the literature regarding the appropriate mode of delivery: scheduled cesarean section or assisted normal vaginal delivery. ${ }^{39}$ Both have their own advantages and disadvantages. In normal vaginal delivery, there is less blood loss (500 mL), less change in blood volume and other hemodynamic factors, less thromboembolic risk, and fewer infections, but the disadvantages include stress and pain period, increased sympathetic activity leading to increased $\mathrm{BP}$, and pulse rate, which puts stress on the right ventricle. Also, labor-induced acidosis, hypoxia, and hypercapnia occur. Regular monitoring of electrocardiogram (ECG), pulse oximetry, central venous pressure, and intra-arterial BP is required; hence, it should be constructed in an intensive care unit (ICU) setting. ${ }^{9}$ It should be executed preferably in left lateral position to diminish pressure effect on the IVC. Nitrous oxide $\left(\mathrm{N}_{2} \mathrm{O}\right)$ should be avoided as it causes vasoconstriction of the pulmonary vasculature.

On the contrary, cesarean section provides a more regulated environment for delivery. It is done electively under optimal conditions. It avoids lengthy labor but has the disadvantage of the effect of anesthesia and high postsurgical fluid shift. ${ }^{8,19}$ Cesarean sections are planned around 32 to 36 week of gestation to prevent the woman going into spontaneous labor.

Irrespective of the mode of delivery, PAH should be well controlled. Some centers start intravenous (IV) epoprostenol therapy shortly before delivery, though there are no studies indicating the improvement in results. Even with well-controlled PAH prior to delivery, there have been deterioration and death postpartum; hence, some centers continue IV epoprostenol even after delivery.

\section{Anesthesia}

Anesthesia is administrated to prevent pain, hypoxemia, hypercapnia, and acidosis, which increase the PVR and pulmonary pressures. ${ }^{15}$ It should be given by the trained anesthetist to prevent rise in $\mathrm{CO}$ and pulmonary pressure with subsequent uterine contraction. Controversy persists regarding general versus local anesthesia..$^{40}$

The benefits of regional anesthesia show decreased effect on contractions of the heart and pulmonary resistance, but at the same time, there is a increased bleeding risk as compared with general anesthesia ( - Table 1). ${ }^{23,41,42}$

Table 1 Modes of anesthesia and delivery

\begin{tabular}{|c|c|c|c|c|c|}
\hline & Number & Mode of delivery & Anesthesia administration & Maternal mortality & Fetal mortality \\
\hline Bédard et al ${ }^{22}$ & $\begin{array}{l}73 \mathrm{IPAH} \\
29 \mathrm{CHD} \\
29 \mathrm{OPH}\end{array}$ & $\begin{array}{l}\text { Vaginal } 7-30 \% \\
\text { CS 70-93\% }\end{array}$ & $\begin{array}{l}\text { Regional 28-67\% } \\
\text { General 29-43\% }\end{array}$ & $17-33 \%$ & $10-13 \%$ \\
\hline Kiely et al ${ }^{29}$ & 10 & CS & Regional & $10 \%$ & 0 \\
\hline Jaïs et $\mathrm{al}^{21}$ & 20 & $\begin{array}{l}\text { Vaginal 5\% } \\
\text { CS 95\% }\end{array}$ & $\begin{array}{l}\text { Regional 80\% } \\
\text { General 20\% }\end{array}$ & $20 \%$ & $10 \%$ \\
\hline Duarte et al ${ }^{23}$ & 12 & CS 100\% & $\begin{array}{l}\text { Regional 66\% } \\
\text { General 25\% }\end{array}$ & $16.7 \%$ & 0 \\
\hline Mongale et $\mathrm{a}^{42}$ & 19 & $\begin{array}{l}\text { Vaginal } 42 \% \\
\text { CS 58\% }\end{array}$ & $\begin{array}{l}\text { Regional 50\% } \\
\text { General 50\% }\end{array}$ & & \\
\hline
\end{tabular}

Abbreviations: CHD, congenital heart disease; CS, cesarean section; IPAH, idiopathic pulmonary arterial hypertension; OPH, other pulmonary hypertension. 


\section{Postnatal Care}

Maximum deaths in pregnant women with PAH occur within the first month post-delivery. During delivery there is a surge in the BP both systolic and diastolic due to pressure on the abdominal aorta by the contracting uterus causing autotransfusion and a rise in peripheral vascular resistance. Also, because of relief of caval compression by the gravid uterus, there is temporary increase in venous return, resulting in increased hemodynamic stress and increased incidence of right heart failure. Risk of pulmonary embolism persists post-delivery; hence, continued patient monitoring and supportive management are warranted to avoid right-sided heart failure. ${ }^{43}$ Postpartum women with $\mathrm{PAH}$, hence, are managed with inhaled NO, inhaled iloprost, IV epoprostenol, systemic vasopressors, and inotropes and oxytocin. However, oxytocin should be used with care as it causes hypotension and reflex tachycardia.

Breast-feeding is to be avoided as pulmonary vasodilators are secreted in the breast milk. Also, prolactin has negative effect on myocardium. Hence close long-term follow-up is recommended.

Babies of PAH mothers are smaller than term babies and should be taken care of in premature care units.

\section{European Society of Cardiology Guidelines for Pregnant Patients with Pulmonary Arterial Hypertension}

In accordance with the European Society of Cardiology 2018 guidelines, mortality rate in pregnant women with $\mathrm{PAH}$ is approximately 16 to $30 \%$, with the major contributory causes being pulmonary hypertensive crisis, pulmonary thromboembolism, and right-sided heart failure. The fetal and neonatal mortality ranges from 0 to $30 \%$. The guidelines recommend against pregnancy and in favor of contraception and early termination in these patients. ${ }^{44}$

Patient counseling about the risk and complications of pregnancy and the possibility of inheritance in heritable PAH should be done. If the woman still desires to continue the pregnancy, a regular weekly follow-up is recommended up to third trimester in a PAH specialist hospital. Symptomatic patients are advised bedrest, and supplementary risk factors (like air travel) should be circumvented.

Patients should be risk-stratified as to low versus high risk. Risk factors for maternal mortality include the severity of PAH, late hospital admissions, and administration of general anesthesia. Early combination therapy is favored in pregnant patients with PAH. Patient individualization is recommended. Patients with adequate control on CCBs and vasodilators represent the low-risk subset, and CCBs should be continued in them as should be IV therapies. Bosentan and other ERAs may cause embryopathies; hence, they are contraindicated.

The guidelines also emphasize the role of pregnancy heart team in deciding the optimal time and mode of delivery. Regional anesthesia is recommended along with aggressive peri- and postpartum intensive care.

\section{Gestational Pulmonary Arterial Hypertension}

In a few instances, PAH manifest for the first time during pregnancy. This is often difficult to diagnose as symptoms of pregnancy and PAH overlap and requires high index of suspicion so as to start early treatment and avoid complications. Mol et al came across a unique case in which PAH developed only at the time of pregnancies and resolved spontaneously after delivery or termination of pregnancy. ${ }^{45}$

The etiopathogenesis of gestational PAH could be either an inadequate production of vasodilators causing pulmonary arterial vasodilation or an inadequate response to these mediators. Though the literature cites occasional case reports for gestational PAH, the actual prevalence might be multifold. Hence in symptomatic patients, this possibility should be entertained and echocardiogram reviewed in the postpartum state.

Current data suggest higher complication rates in these patients due to delayed diagnosis and initiation of PAHrelated therapies. Depending on the time of diagnosis, termination of pregnancy should be offered to them. Caution is required during interpretation of false-positive echocardiograms secondary to high COs and raised pulmonary pressures during pregnancy.

\section{Indian Studies on Pulmonary Arterial Hypertension}

Pulmonary arterial hypertension in pregnancy has several interesting case reports from the Indian subcontinent. Subbaiah et al, in a retrospective cohort of pregnant patients with $\mathrm{PAH}$, reported higher incidence of maternal as well as fetal complications with rising severity of PAH. ${ }^{46}$ Puri et al reported favorable outcome in a pregnant patient with PAH when managed in a tertiary care center. ${ }^{47}$ The authors stressed upon adequate management of $\mathrm{PAH}$ as well as pregnancy-related issues in these patients with aggressive intensive care.

An interesting case report was published by Hasan et al wherein pulmonary artery pressures significantly abated, following spontaneous development of pulmonary arteriovenous malformation in an IPAH patient. ${ }^{48}$

\section{Conclusion}

Pulmonary arterial hypertension and pregnancy outcomes have been known to be grave with high maternal and fetal mortality. Termination of pregnancy, whenever feasible, continues to be the recommended in this subset of patients. However, with upcoming PAH-specific therapies and development in intensive care modules in PAH specialist centers, pregnancy can be fruitful especially in the low-risk patients. Hence, a multidisciplinary approach with astute, prompt, and aggressive team management is recommended in this subset of patients. 


\section{References}

1 Galiè N, Humbert M, Vachiery JL, et al; ESC Scientific Document Group. 2015 ESC/ERS guidelines for the diagnosis and treatment of pulmonary hypertension: the Joint Task Force for the Diagnosis and Treatment of Pulmonary Hypertension of the European Society of Cardiology (ESC) and the European Respiratory Society (ERS): Endorsed by: Association for European Paediatric and Congenital Cardiology (AEPC), International Society for Heart and Lung Transplantation (ISHLT). Eur Heart J 2016;37(1):67-119

2 Rosengarten D, Blieden LC, Kramer MR. Pregnancy outcomes in pulmonary arterial hypertension in the modern management era. Eur Respir J 2012;40(5):1304-1305

3 Hoendermis ES. Pulmonary arterial hypertension: an update. Neth Heart J 2011;19(12):514-522

4 Lane CR, Trow TK. Pregnancy and pulmonary hypertension. Clin Chest Med 2011;32(1):165-174

5 Ladouceur M, Benat L, Radojevic J, et al. Pregnancy outcome in patients with $\mathrm{PAH}$ associated with congenital heart disease. Heart 2017

6 Tihtonen K, Kööbi T, Yli-Hankala A, Uotila J. Maternal hemodynamics during cesarean delivery assessed by wholebody impedance cardiography. Acta Obstet Gynecol Scand 2005;84(4):355-361

7 Olsson KM, Jais X. Birth control and pregnancy management in pulmonary hypertension. Semin Respir Crit Care Med 2013;34(5):681-688

8 Madden BP. Pulmonary hypertension and pregnancy. Int J Obstet Anesth 2009;18(2):156-164

9 Hsu CH, Gomberg-Maitland M, Glassner C, Chen JH. The management of pregnancy and pregnancy-related medical conditions in pulmonary arterial hypertension patients. Int J Clin Pract Suppl 2011;175(172):6-14

10 Regitz-Zagrosek V, Blomstrom Lundqvist C, Borghi C, et al; European Society of Gynecology (ESG); Association for European Paediatric Cardiology (AEPC); German Society for Gender Medicine (DGesGM); ESC Committee for Practice Guidelines. ESC guidelines on the management of cardiovascular diseases during pregnancy: the Task Force on the Management of Cardiovascular Diseases during Pregnancy of the European Society of Cardiology (ESC). Eur Heart J 2011;32(24):3147-3197

11 Hunter S, Robson SC. Adaptation of the maternal heart in pregnancy. Br Heart J 1992;68(6):540-543

12 Langesæter E, Dyer RA. Maternal haemodynamic changes during spinal anaesthesia for caesarean section. Curr Opin Anaesthesiol 2011;24(3):242-248

13 Simonneau G, Robbins IM, Beghetti M, et al. Updated clinical classification of pulmonary hypertension. J Am Coll Cardiol 2009;54(1, Suppl):S43-S54

14 McMillan E, Martin WL, Waugh J, et al. Management of pregnancy in women with pulmonary hypertension secondary to SLE and anti-phospholipid syndrome. Lupus 2002;11(6):392-398

15 Gaine SP, Rubin LJ. Primary pulmonary hypertension. Lancet 1998;352(9129):719-725

16 Wylie BJ, Epps KC, Gaddipati S, Waksmonski CA. Correlation of transthoracic echocardiography and right heart catheterization in pregnancy. J Perinat Med 2007;35(6):497-502

17 Hoeper MM, Lee SH, Voswinckel R, et al. Complications of right heart catheterization procedures in patients with pulmonary hypertension in experienced centers. J Am Coll Cardiol 2006;48(12):2546-2552

18 Weiss BM, Zemp L, Seifert B, Hess OM. Outcome of pulmonary vascular disease in pregnancy: a systematic overview from 1978 through 1996. J Am Coll Cardiol 1998;31(7):1650-1657
19 Sliwa K, van Hagen IM, Budts W, et al; ROPAC investigators. Pulmonary hypertension and pregnancy outcome-data from the registry of pregnancy and cardiac disease of the European Society of Cardiology. Eur J Heart Fail 2016; 18(9):1119-1128

20 Smith JS, Mueller J, Daniels CJ. Pulmonary arterial hypertension in the setting of pregnancy: a case series and standard treatment approach. Hai 2012;190(2):155-160

21 Jaïs X, Olsson KM, Barbera JA, et al. Pregnancy outcomes in pulmonary arterial hypertension in the modern management era. Eur Respir J 2012;40(4):881-885

22 Bédard E, Dimopoulos K, Gatzoulis MA. Has there been any progress made on pregnancy outcomes among women with pulmonary arterial hypertension? Eur Heart J 2009; 30(3):256-265

23 Duarte AG, Thomas S, Safdar Z, et al. Management of pulmonary arterial hypertension during pregnancy: a retrospective, multicenter experience. Chest 2013;143(5):1330-1336

24 Katsuragi S, Yamanaka K, Neki R, et al. Maternal outcome in pregnancy complicated with pulmonary arterial hypertension. Circ J 2012;76(9):2249-2254

25 Hemnes AR, Kiely DG, Cockrill BA, et al. Statement on pregnancy in pulmonary hypertension from the Pulmonary Vascular Research Institute. Pulm Circ 2015;5(3):435-465

26 Thorne S, Nelson-Piercy C, MacGregor A, et al. Pregnancy and contraception in heart disease and pulmonary arterial hypertension. J Fam Plann Reprod Health Care 2006;32(2):75-81

27 Mantha S, Karp R, Raghavan V, Terrin N, Bauer KA, Zwicker JI. Assessing the risk of venous thromboembolic events in women taking progestin-only contraception: a meta-analysis. BMJ 2012;345:e4944

28 Austin ED, Loyd JE, Phillips JA III. Heritable pulmonary arterial hypertension. In: Pagon RA, Adam MP, Ardinger HH, et al, eds. GeneReviews. Seattle, WA: University of Washington; 2002. www.ncbi.nlm.nih. gov/books/NBK1485. Accessed December 17,2018

29 Kiely DG, Condliffe R, Webster V, et al. Improved survival in pregnancy and pulmonary hypertension using a multiprofessional approach. BJOG 2010;117(5):565-574

30 Terek D, Kayikcioglu M, Kultursay H, et al. Pulmonary arterial hypertension and pregnancy. J Res Med Sci 2013;18(1):73-76

31 Warnes CA. Pregnancy and pulmonary hypertension. Int J Cardiol 2004;97(Suppl 1):11-13

32 Berger G, Azzam ZS, Hoffman R, Yigla M. Coagulation and anticoagulation in pulmonary arterial hypertension. Isr Med Assoc J 2009;11(6):376-379

33 Stone SE, Morris TA. Pulmonary embolism during and after pregnancy. Crit Care Med 2005;33(10, Suppl):S294-S300

34 Rich S, Kaufmann E, Levy PS. The effect of high doses of calcium-channel blockers on survival in primary pulmonary hypertension. N Engl J Med 1992;327(2):76-81

35 Tsapenko MV, Tsapenko AV, Comfere TBO, Mour GK, Mankad SV, Gajic O. Arterial pulmonary hypertension in noncardiac intensive care unit. Vasc Health Risk Manag 2008;4(5):1043-1060

36 Archer SL, Michelakis ED. Phosphodiesterase type 5 inhibitors for pulmonary arterial hypertension. N Engl J Med 2009;361(19):1864-1871

37 Strauss WL, Edelman JD. Prostanoid therapy for pulmonary arterial hypertension. Clin Chest Med 2007;28(1):127-142, ix ix

38 Channick RN. Combination therapy in pulmonary arterial hypertension. Am J Cardiol 2013;111(8 Suppl):16C-20C

39 Siu SC, Sermer M, Colman JM, et al; Cardiac Disease in Pregnancy (CARPREG) Investigators. Prospective multicenter study of pregnancy outcomes in women with heart disease. Circulation 2001;104(5):515-521 
40 Uebing A, Steer PJ, Yentis SM, Gatzoulis MA. Pregnancy and congenital heart disease. BMJ 2006;332(7538):401-406

41 Bonnin M, Mercier FJ, Sitbon O, et al. Severe pulmonary hypertension during pregnancy: mode of delivery and anesthetic management of 15 consecutive cases. Anesthesiology 2005;102(6):1133-1137, discussion 5A-6A

42 Monagle J, Manikappa S, Ingram B, Malkoutzis V. Pulmonary hypertension and pregnancy: the experience of a tertiary institution over 15 years. Ann Card Anaesth 2015;18(2):153-160

43 Chamaidi A, Gatzoulis MA. Heart disease and pregnancy. Hellenic J Cardiol 2006;47(5):275-291

44 Regitz-Zagrosek V, Roos-Hesselink JW, Bauersachs J, et al; ESC Scientific Document Group. 2018 ESC guidelines for the management of cardiovascular diseases during pregnancy. Eur Heart J 2018;39(34):3165-3241
45 Moll M, Payne JG, Tukey MH, Farber HW. Gestational pulmonary arterial hypertension. Pulm Circ 2015;5(4):730-733

46 Subbaiah M, Kumar S, Roy KK, Sharma JB, Singh N. Pregnancy outcome in women with pulmonary arterial hypertension: single-center experience from India. Arch Gynecol Obstet 2013;288(2):305-309

47 Puri S, Wander GS, Chhabra S. Primary pulmonary hypertension in pregnancy: a case report. Obst \& Gynae Today 2007;XII(11):507-508

48 Hasan A, Sastry BK, Aleem MA, Reddy G, Mahmood S. Regression of pulmonary artery hypertension due to development of a pulmonary arteriovenous malformation. Indian Heart J 2014;66(5):535-538 